\title{
OPTIMIZATION OF AN ANIMAL TEST PROTOCOL FOR TOXICOGENOMICS STUDIES (I); REQUIREMENT STUDY OF A PROTOCOL
}

\author{
Kayo SUMIDA ${ }^{1}$, Koichi SAITO ${ }^{1}$, Kenji OEDA ${ }^{1}$, Masanori OTSUKA ${ }^{2}$, Kazunari TSUJIMURA ${ }^{2}$, \\ Hideki MIYAURA ${ }^{2}$, Masaru SEKIJIMA ${ }^{3}$, Koji NAKAYAMA ${ }^{3}$, Yukiko KAWANO ${ }^{3}$, \\ Yuki KAWAKAMI ${ }^{3}$, Makoto ASAMOTO ${ }^{4}$ and Tomoyuki SHIRAI ${ }^{4}$ \\ ${ }^{1}$ Sumitomo Chemical Co., Ltd., \\ 3-1-98 Kasugade-naka, Konohana-ku, Osaka 554-8558, Japan \\ ${ }^{2}$ Chemical Evaluation and Research Institute, 1-4-25 Koraku, Bunkyo-ku, Tokyo 112-0004, Japan \\ ${ }^{3}$ Mitsubishi Chemical Safety Institute Ltd., 14 Sunayama, Kamisu Ibaraki 314-0255, Japan \\ ${ }^{4}$ Graduate School of Medical Sciences, Nagoya City University, \\ 1 Kawasumi, Mizuho-cho, Mizuho-ku, Nagoya 467-8601, Japan
}

(Received October 2, 2006; Accepted November 8, 2006)

\begin{abstract}
Toxicogenomics is a promising new tool for prediction of chemical toxicities including carcinogenicity in a relatively short period. However, it is important to develop a reliable animal test protocol for toxicogenomics studies. The preparation of RNA and tissues is also crucial, since it greatly influences outcomes of gene expression analysis.

In the present study, we examined an animal test protocol by comparing gene expression data from different conditions and proposed a reliable animal test protocol for toxicogenomic studies.

With regard to the preparation of tissues and RNA, here we present evidence that quality of RNA and tissues is well-preserved even after freezer storage for up to 2.5 years. Gene expression levels were compared using a GeneChip System (RGU34A, Affymetrix, Santa Clara, CA, USA) between RNA samples that were freshly prepared, stored at $-80^{\circ} \mathrm{C}$ or re-prepared from tissue kept at $-20^{\circ} \mathrm{C}$. None showed degradation and no significant differences in expression were evident among the three sets of samples. The data demonstrate that gene expression analysis by DNA microarray is suitable for RNA or tissues that have been stored at an appropriate temperature.
\end{abstract}

KEY WORDS: Gene expression analysis, Toxicogenomics, Animal test protocol, RNA Integrity

\section{INTRODUCTION}

It is our goal to establish a reliable new technology for detection of carcinogenic potential of environmental chemicals based on specific gene alterations. In Japan, a 5-year national project has started to establish toxicogenomics for prediction of hepatocarcinogenicity of chemicals using Fischer 344 rats in 2001 (the New Energy and Industrial Technology Development Organization (NEDO) Toxicogenomics Project). The long-term aim is to build a database of gene- and protein-expression profiles and develop data mining algo- rithms using reference carcinogenic and non-carcinogenic compounds to establish a screening system for evaluation. For this purpose, male Fischer 344 rats are treated by daily oral gavage with known hepato-carcinogenic, non-hepato-carcinogenic or non-carcinogenic compounds at two dose levels for 28 days, with livers sampled at Days 1, 3, 7, 14 and 28. The gene expression levels in the samples $(n=4-5)$ are being monitored with in-house microarray (NEDO-ToxArray) and a GeneChip System (RGU34A, Affymetrix) and a gene expression database for 85 chemicals has been constructed in our project.

Correspondence: Kayo SUMIDA (E-mail: sumida@sc.sumitomo-chem.co.jp) 
To achieve success, it is important to develop a reliable animal test protocol for toxicogenomics studies. One of the issues in database development is the degree of comparability of biological and gene expression data across laboratories. It is craved to establish a standardized animal test protocol for our project and it is deemed to be useful for other toxicogenomics studies. The standardized animal test protocol requires that the variance of data fall within the estimated range. A lot of animal tests have been conducted in toxicity studies in accordance with various guidelines and it is generally accepted that the results of animal tests including histopathological and clinical biochemical data were in a certain range. However, the degree of comparability of gene expression data across laboratories is not clear. As described above, our goal is to establish a reliable new technology for detection of carcinogenic potential of environmental chemicals based on specific gene alterations. For this reason, the developed animal test protocol requires good comparability of gene expression data across laboratories. When we confirm reasonable agreement in gene expression results among laboratories, the observed discrepancies in expression profiles for individual genes might be due to chemical (for example, impure substance), animal, microarray, test reagent, procedure of animal testing or gene expression analysis. In the present study, we therefore examined an animal test protocol by comparing gene expression data on the same microarray platform with a focus on procedure of animal testing; comparison of the methods for euthanasia, time-course analysis of quality of RNA after sampling, comparison of the gene expression profiles within a liver lobe, and comparison of the gene expression profiles among the liver lobes. We conducted a series of experiments to address these matters and developed an animal test protocol based on the results. According to the proposed animal test protocol, we started the animal tests in order to create the database in our project. We tried to decrease the differences of gene expression data across laboratories as much as possible by matching the conditions of animal tests.

The success of the microarray process in determining differential gene expression of thousands of genes is dependent upon the quality and integrity of the starting RNA, this being particularly true of direct labeling via reverse transcription procedures. It is particularly important to confirm whether RNA degradation has occurred in samples or tissues for gene expression analysis after long-term storage. Although a moderate degree of RNA degradation does not preclude meaningful results for microarray analysis or reverse transcription PCR (RT-PCR), more extensive degradation necessitates the exclusion of the affected samples from further study (Miller et al., 2004; Schoor et al., 2003). In the present study, we therefore examined alteration of gene expression after long-term preservation of RNA samples or tissues. RNA samples were kept frozen at $-80^{\circ} \mathrm{C}$ while tissues were frozen at $-20^{\circ} \mathrm{C}$ in RNA stabilization solution for 2.5 years. After checking RNA integrity using a 2100 Bioanalyzer (Agilent Technologies, Palo Alto, CA, USA), gene expression analysis was carried out using a GeneChip System (Affymetrix). The resulting data were compared with the initial expression data obtained with fresh RNA samples at the outset of the experiment. We also examined deterioration of RNA with freezing and thawing by alteration of gene expression. Total RNA was freeze-thawed 2, 5 or 10-times repeatedly and applied for gene expression analysis. As in the case of evaluation of quality of RNA and tissues stored in freezers, the resulting data were compared with the initial expression data.

\section{MATERIALS AND METHODS}

\section{Chemicals}

Chemicals tested in the present study were: carbon tetrachloride (purity $>99.8 \%$ ) purchased from Wako Pure Chemical Industries (Osaka, Japan), clofibrate from Sigma Chemical Co. (St. Louis, MO, USA) and corn oil from Nacalai Tesque (Kyoto, Japan).

\section{Comparison of the methods for euthanasia}

Male Fischer 344 rats (SPF; 7 weeks of age) were obtained from Charles River Japan, Inc. and two of the rats were killed by decapitation. Two other pairs of rats were anesthetized with $\mathrm{CO}_{2}-\mathrm{O}_{2}\left(\mathrm{CO}_{2}: \mathrm{O}_{2}=2: 1\right.$, $10 \mathrm{~L} / \mathrm{min}$ ) or diethylether and exsanguinated via the abdominal aorta. In all cases, liver samples were immediately frozen with liquid nitrogen and stored at $-80^{\circ} \mathrm{C}$ until extraction of total RNA. A portion of the left lateral lobe was taken for gene expression analysis and total RNA was extracted with TRIzol Reagent (Invitrogen, CA, USA). Pooled RNA samples from 2 animals were run on one array and gene expression levels measured with a GeneChip System (RGU34A, Affymetrix).

\section{Time-course analysis of quality of RNA after sam- pling}

A male Fischer 344 rat (SPF; 6 weeks of age) was 
Optimization of an animal test protocol for toxicogenomics studies.

obtained from Charles River Japan, Inc. (Atsugi, Japan) and killed by decapitation. The removed liver was left for $0,10,20$ or $30 \mathrm{~min}$ on ice and portions of the left lateral lobe were taken for gene expression analysis at each time point, immediately frozen in liquid nitrogen and stored at $-80^{\circ} \mathrm{C}$ until extraction of total RNA with TRIzol Reagent (Invitrogen). Quantification and assessment of ribosomal RNA integrity were carried out using a 2100 Bioanalyzer (Agilent Technologies) and gene expression levels were measured using a GeneChip System (RGU34A, Affymetrix).

\section{Comparison of gene expression profiles within a liver lobe}

A male Fischer 344 rat (SPF; 7 weeks of age) was obtained from Charles River Japan, Inc. and exsanguinated via the abdominal aorta under diethylether anesthesia. Liver samples were immediately frozen in liquid nitrogen and stored at $-80^{\circ} \mathrm{C}$ until extraction of total RNA. Ten portions (Points A-J) within the left lateral lobe were taken for gene expression analysis. Total RNA was extracted with TRIzol Reagent (Invitrogen) and gene expression levels were measured using a GeneChip System (RGU34A, Affymetrix).

\section{Comparison of the gene expression profiles among the liver lobes}

Male Fischer 344 rats (SPF; 8 weeks of age) were obtained from Charles River Japan, Inc. and treated with clofibrate $(300 \mathrm{mg} / \mathrm{kg} / \mathrm{day}$, po) or vehicle (corn oil) alone for 7 days (each $n=2$ ) before being killed by decapitation. Liver samples were immediately frozen in liquid nitrogen and stored at $-80^{\circ} \mathrm{C}$ until total RNA extraction. Half of the left lateral lobe (including the portal vein), the other half of the left lateral lobe, the left medial lobe, the right medial lobe, the right lateral lobe and the caudate lobe were taken for gene expression analysis. Total RNA was extracted with TRIzol Reagent (Invitrogen) and gene expression levels were measured using a GeneChip System (RGU34A, Affymetrix). Pooled RNA samples from paired animals were run on one array.

\section{Evaluation of quality of RNA and tissues stored in freezers}

Male Fischer 344 rats (SPF; 4 weeks of age) were obtained from Charles River Japan, Inc. (Atsugi, Japan) and treated with clofibrate $(250 \mathrm{mg} / \mathrm{kg} /$ day, po), carbon tetrachloride $(50 \mathrm{mg} / \mathrm{kg} / \mathrm{day}$, po) or vehicle (corn oil) alone for 14 days $(n=5)$. Total RNA was extracted from liver pieces using a Biorobot 3000 (Qiagen, Hilden, Germany) before quantification and assessment of ribosomal RNA integrity using a 2100 Bioanalyzer (Agilent Technologies). Concentrations of total RNA were measured with an Amersham-Pharmacia spectrophotometer, model Ultraspec 3100pro and samples were either immediately processed for gene expression analysis or stored at $-80^{\circ} \mathrm{C}$ until eventual use. Gene expression levels were measured using a GeneChip System (RGU34A, Affymetrix). Pooled RNA from 5 animals was run on one array.

\section{Deterioration of RNA with freezing and thawing}

A male Fischer 344 rat (SPF; 6 weeks of age) was obtained from Charles River Japan, Inc. (Atsugi, Japan) and killed by decapitation. Total RNA from liver was extracted with TRIzol Reagent (Invitrogen), freeze-thawed 2, 5 or 10-times repeatedly and applied for gene expression analysis. The freeze-thawing process involved freezing at $-80^{\circ} \mathrm{C}$ and thawing at $65^{\circ} \mathrm{C}$ for $5 \mathrm{~min}$. Gene expression levels were measured using a GeneChip System (RGU34A, Affymetrix).

\section{Gene expression analysis}

Gene expression analysis was carried out with a GeneChip System (Affymetrix) following the manufacturer's protocol (Lockhart et al., 1996). Briefly, double-stranded cDNAs were synthesized from $10 \mu \mathrm{g}$ of total RNA and used as templates for in vitro transcription. Fragmented in vitro transcripts were hybridized overnight onto RGU34A rat microarrays (Affymetrix). The hybridized samples were stained, washed and scanned in an Affymetrix GeneArray scanner and the obtained image files were analyzed with the Affymetrix data suite system, Microarray Suite 5.0 (MAS 5.0). We then examined tab-delimited files containing data regarding the relative level of expression of a transcript (Signal) to determine reliable detection (Detection Call). The derived Signal values were globally normalized and targeted to all probe sets equal to 100 before comparative analysis to examine gene expression differences between treatment and control samples. From the resulting tab-delimited files, data regarding alteration in the gene expression (Change Call) and the magnitude and direction of change (Signal Log Ratio, base is 2.) were obtained.

We did not use any statistical tests to select probe sets because the pooled RNA from 1-5 animals was run on one array and therefore there was only a biological replicate of one. All those showing greater than or equal to "1" for the Signal Log Ratio, "I (increase)" for 
Change Call and "P (present)" for Detection Call in an experimental (treatment) array were regarded as upregulated probe sets. Those showing less than or equal to "-1" for the Signal Log Ratio, "D (decrease)" for Change Call and "P (present)" A for Detection Call in the baseline (control) array were regarded as downregulated.

\section{RESULTS AND DISCUSSION}

\section{Comparison of methods for euthanasia}

To examine the effects of the method chosen for euthanasia on the gene expression data, a comparison of decapitation and exsanguination under $\mathrm{CO}_{2}-\mathrm{O}_{2}$ or diethylether anesthesia was performed. The number of the probe sets with differences in expression is shown in Table 1. Probe sets with altered expression between decapitation and exsaguination under $\mathrm{CO}_{2}-\mathrm{O}_{2}$ anesthesia are 12 increased and 8 decreased, very small numbers when considering the total of 8799 . There were 11 increased and 30 decreased probe sets with altered expression between decapitation and exsanguination under diethylether anesthesia and 14 increased and 14 decreased probe sets between exsanguination under
$\mathrm{CO}_{2}-\mathrm{O}_{2}$ and diethylether anesthesia. When identical RNA samples were analyzed with RGU34A arrays and the expression data were compared, it was observed that there were also 12 increased and 2 decreased probe sets out of the total of 8799 , about $0.16 \%$ of total probe sets of RGU34A. The Signal and Signal Log Ratio values of probe sets with discrepancies were relatively low and alteration of probe sets with discrepancies was regarded as an experimental error. The variation range of Signal values of probe sets with differences in expression in a comparison of the methods for euthanasia was similar to that of 14 probe sets with discrepancies.

Taken together, there were no significant differences among the gene expression data with the three methods for euthanasia.

\section{Time-course analysis of quality of RNA after liver sampling}

Expression data at $0,10,20$ or $30 \mathrm{~min}$ after sampling were compared. There were 16 down-regulated out of 8799 probe sets of RGU34A at $10 \mathrm{~min}, 6$ increased and 14 decreased at $20 \mathrm{~min}$, and 5 increased and 12 decreased at 30 min. Fig. 1 illustrates a Venn

Table 1. The number of probe sets with differences in expression.

\begin{tabular}{lcc} 
& \multicolumn{2}{c}{ Number of probe sets } \\
\cline { 2 - 3 } & Increased & Decreased \\
\hline Decapitation - Exsaguination under $\mathrm{CO}_{2}-\mathrm{O}_{2}$ anesthesia & 12 & 8 \\
Decapitation - Exsaguination under diethylether anesthesia & 11 & 30 \\
Exsaguination under $\mathrm{CO}_{2}-\mathrm{O}_{2}$ anesthesia - Exsaguination under diethylether anesthesia & 14 & 14 \\
\hline
\end{tabular}
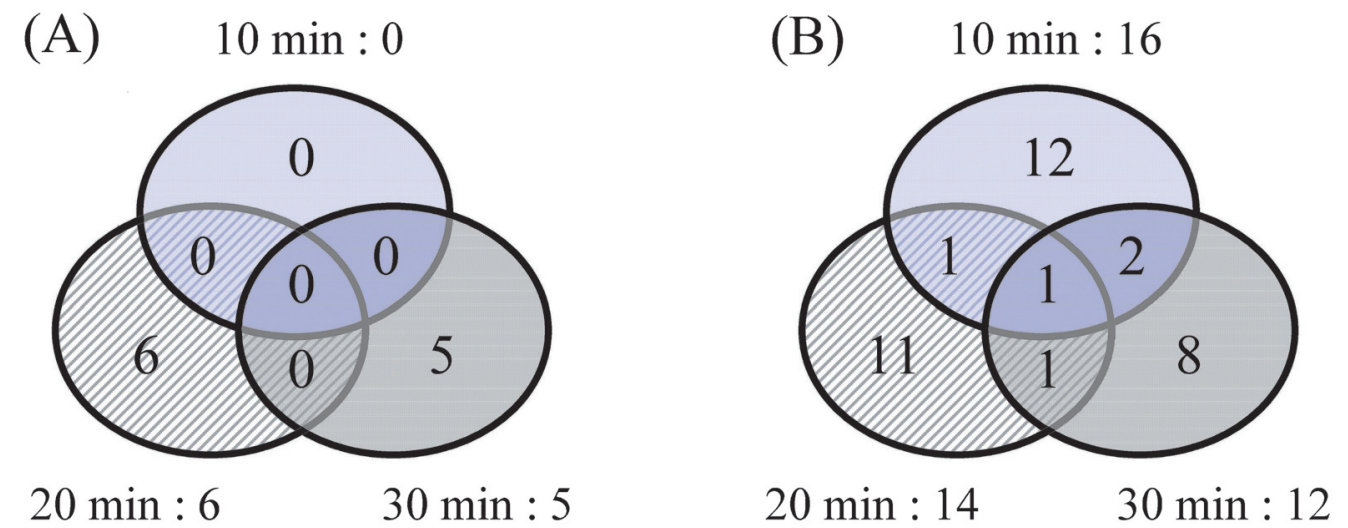

Fig. 1. Venn diagram of significant alterations in gene expression observed. Numbers present those of probe sets with expression significantly altered. (A) Increased probe sets. (B) Decreased probe sets. 
Optimization of an animal test protocol for toxicogenomics studies.

diagram of significant alterations in gene expression observed. Cyclin-dependent kinase inhibitor 1C p57 was decreased at all time points and the EST (probe set name: X05472cds\#2_at) at both 20 and $30 \mathrm{~min}$. However, it was observed that the Signal Log Ratio for cyclin-dependent kinase inhibitor $1 \mathrm{C}$ p57 was -4.06 at $10 \mathrm{~min},-3.47$ at $20 \mathrm{~min}$ and -1.51 at $30 \mathrm{~min}$, with no time-dependent decrease indicative of degradation. Similar results were obtained for EST (probe set name: X05472cds\#2_at).

Taken together, there were no significant differences in gene expression profiles when liver was frozen with liquid nitrogen (or placed in RNAlater) within 30 min after sampling.

\section{Comparison of gene expression profiles within a liver lobe}

Expression data for Point B-J are compared with data of Point A, with numbers of increased or decreased probe sets, in Table 2. There were 1-33 increased and 1-11 decreased out of 8799 probe sets of RGU34A, but the Signal and Signal Log Ratio values for most of these were relatively low. The variation range of Signal values of probe sets with differences in expression was similar to that of 14 probe sets with discrepancies described above (Comparison of methods for euthanasia).

Taking these results into account, there were no significant differences in gene expression profiles within the left lateral lobe.

\section{Comparison of gene expression profiles among liver lobes}

Numbers of altered probe sets for different lobes are shown in Table 3, with some 3-14 increased and 359 decreased out of the total of 8799 with RGU34A in

Table 2. The number of probe sets with differences in expression.

\begin{tabular}{ccc}
\hline & \multicolumn{2}{c}{ Number of probe sets } \\
\cline { 2 - 3 } & Increased & Decreased \\
\hline A-B & 33 & 6 \\
A-C & 14 & 2 \\
A-D & 19 & 7 \\
A-E & 12 & 4 \\
A-F & 22 & 11 \\
A-G & 8 & 1 \\
A-H & 1 & 5 \\
A-I & 24 & 2 \\
A-J & 29 & 8 \\
\hline
\end{tabular}

Table 3A or 3B. The Signal and Signal Log Ratio values of most of these probe sets were relatively low. In Table 3C, the numbers of up- or down-regulated probe sets in comparison of gene expression data in each lobe between non-treated rats and clofibrate-treated rats are shown. About $80 \%$ of the up-regulated and about $50 \%$ of the down-regulated probe sets overlapped between the data. Discrepancies were found as the expression change became smaller, but most probe sets near the top of the altered lists were found in common. There were many genes that were reported to be up- or downregulated by clofibrate, like lipid binding protein, fatty acid binding protein, acyl-Coenzyme A oxidase, stearoyl-Coenzyme A desaturase, and fatty acid synthase up-regulated and apo-A1, enoyl-Coenzyme A isomerase, cyclin $\mathrm{G}$ and other genes down-regulated (Hamadeh et al., 2002).

In another report, early growth response I, prostaglandin D2 receptor, dentatorubral pallidoluysian atrophy, epoxide hydrolase I, acetyl-Coenzyme A acyltransferase 1, dodecenoyl-Coenzyme A delta isomerase, cyp4b1, cyp7a1, cyp2c37, cyp2b19, fatty acid desaturase I, aldehyde dehydrogenase 1A1, folate hydrolase, acyl-Coenzyme A oxidase, fatty acid Coenzyme A ligase, carboxylesterase 2 and other genes were up-regulated and sulfotransferase hydroxysteroid gene 2, trisephosphate isomerase 1, thioredoxin and other genes were down-regulated by clofibrate on microarray analysis (Jung et al., 2004). Many other genes which are involved in lipid-related, hormone or drug metabolism, proliferation, transcription control, apoptosis, cellular metabolism, immunity, inflammation, coagulation and stress-responses have furthermore been reported to be up- or down-regulated by clofibrate (Kramer et al., 2003). Lists of up- or downregulated probe sets in half of the left lateral lobe (including the portal vein) are shown in Table 4. Many genes are included for which up-regulation by clofibrate is known. For example, acyl-coenzyme A thioesterase 1 , fatty acid binding protein 3, carnitine palmitoyltransferase $1 \mathrm{~b}$, acetyl-coenzyme A acyltransferase 1, enoyl-Coenzyme A, hydratase/3-hydroxyacyl Coenzyme A dehydrogenase, lipoprotein lipase, enoyl coenzyme A hydratase 1 (lipid-related), glutathione $S$ transferase, alpha 1 , epoxide hydrolase 2 and malic enzyme 1 (drug metabolism) are listed near the top of the up-regulated probe sets and apolipoprotein A-IV (lipid-related), cytochrome P450, 1a2, cytochrome P450, 2c39 and hydroxysteroid 11-beta dehydrogenase 1 (drug metabolism or hormone-related) are included among those most down-regulated. Alteration of these 
genes was observed in all liver lobes, so that essential similarity across lobes was concluded.

\section{Evaluation of the quality of RNA and tissues stored in freezers}

A 2100 Bioanalyzer was used for quantification and assessment of the integrity of freshly prepared total RNA, total RNA kept at $-80^{\circ} \mathrm{C}$ for 2.5 years and reprepared RNA from tissues kept at $-20^{\circ} \mathrm{C}$ with RNAlater for the same period. Fig. 2 shows results of gel electrophoresis analysis of total RNA samples from livers of male Fischer 344 rats, which were given 50 $\mathrm{mg} / \mathrm{kg} /$ day carbon tetrachloride for 14 days. The electropherograms feature flat baselines and a relatively flat valley between the two strong fluorescent rRNA peaks. mRNA fluorescence within the context of highquality total RNA was below detection. mRNA accounts for only $1-5 \%$ of a total RNA sample and the rRNA peaks dominate the fluorescence (Aviv and Leder, 1972). RNA from tissue samples can be screened based on the observation that the nucleic acid content represented by $28 \mathrm{~S}$ rRNA should be approximately twice that of $18 \mathrm{~S}$ in total RNA samples for the mRNA quality to be acceptable (Sambrook and Russell, 2001). Our results showed no RNA samples with degradation, even after a period of 2.5 years, and the quality of total RNA samples proved acceptable for DNA microarray analysis.

To assess reproducibility among freshly prepared total RNA, for total RNA kept at $-80^{\circ} \mathrm{C}$ for 2.5 years and re-prepared RNA from tissues kept at $-20^{\circ} \mathrm{C}$ in RNA later for 2.5 years, scatter plots were generated using MAS 5.0 (Fig. 3). The obtained $\mathrm{R}^{2}$ values were 0.9794 and 0.9813 , with a good correlation between gene expression data. The dots in red show probe sets termed Present in both samples, the dots in blue show probe sets having Discordant calls between two samples and the dots in yellow show probe sets were termed Absent in both samples. Results of detection call concordance analysis are shown in Table 5. The

Table 3.

A. The number of probe sets with differences in expression among the liver lobes in non-treated rats.

\begin{tabular}{lcc}
\hline & Number of probe sets \\
\cline { 2 - 3 } & Increased & Decreased \\
\hline Half of the left lateral lobe (including the portal vein) - Other half of the left lateral lobe & 3 & 33 \\
Half of the left lateral lobe (including the portal vein) - Left medial lobe & 3 & 8 \\
Half of the left lateral lobe (including the portal vein) - Right medial lobe & 3 & 24 \\
Half of the left lateral lobe (including the portal vein) - Right lateral lobe & 11 & 5 \\
Half of the left lateral lobe (including the portal vein) - Caudate lobe & 14 & 17 \\
\hline
\end{tabular}

B. The number of probe sets with differences in expression among the liver lobes in clofibrate-treated rats.

\begin{tabular}{lcc} 
& \multicolumn{2}{c}{ Number of probe sets } \\
\cline { 2 - 3 } Half of the left lateral lobe (including the portal vein) - Other half of the left lateral lobe & Increased & Decreased \\
Half of the left lateral lobe (including the portal vein) - Left medial lobe & 11 & 23 \\
Half of the left lateral lobe (including the portal vein) - Right medial lobe & 8 & 10 \\
Half of the left lateral lobe (including the portal vein) - Right lateral lobe & 12 & 59 \\
Half of the left lateral lobe (including the portal vein) - Caudate lobe & 5 & 3 \\
\hline
\end{tabular}

C. The number of probe sets with differences in expression among the liver lobes between clofibrate- and non-treated rats.

\begin{tabular}{lcc} 
& \multicolumn{2}{c}{ Number of probe sets } \\
\cline { 2 - 3 } Half of the left lateral lobe (including the portal vein) & Up-regulated & Down-regulated \\
Other half of the left lateral lobe & 138 & 122 \\
Left medial lobe & 170 & 175 \\
Right medial lobe & 142 & 112 \\
Right lateral lobe & 158 & 119 \\
Caudate lobe & 126 & 91 \\
\hline
\end{tabular}


Optimization of an animal test protocol for toxicogenomics studies.

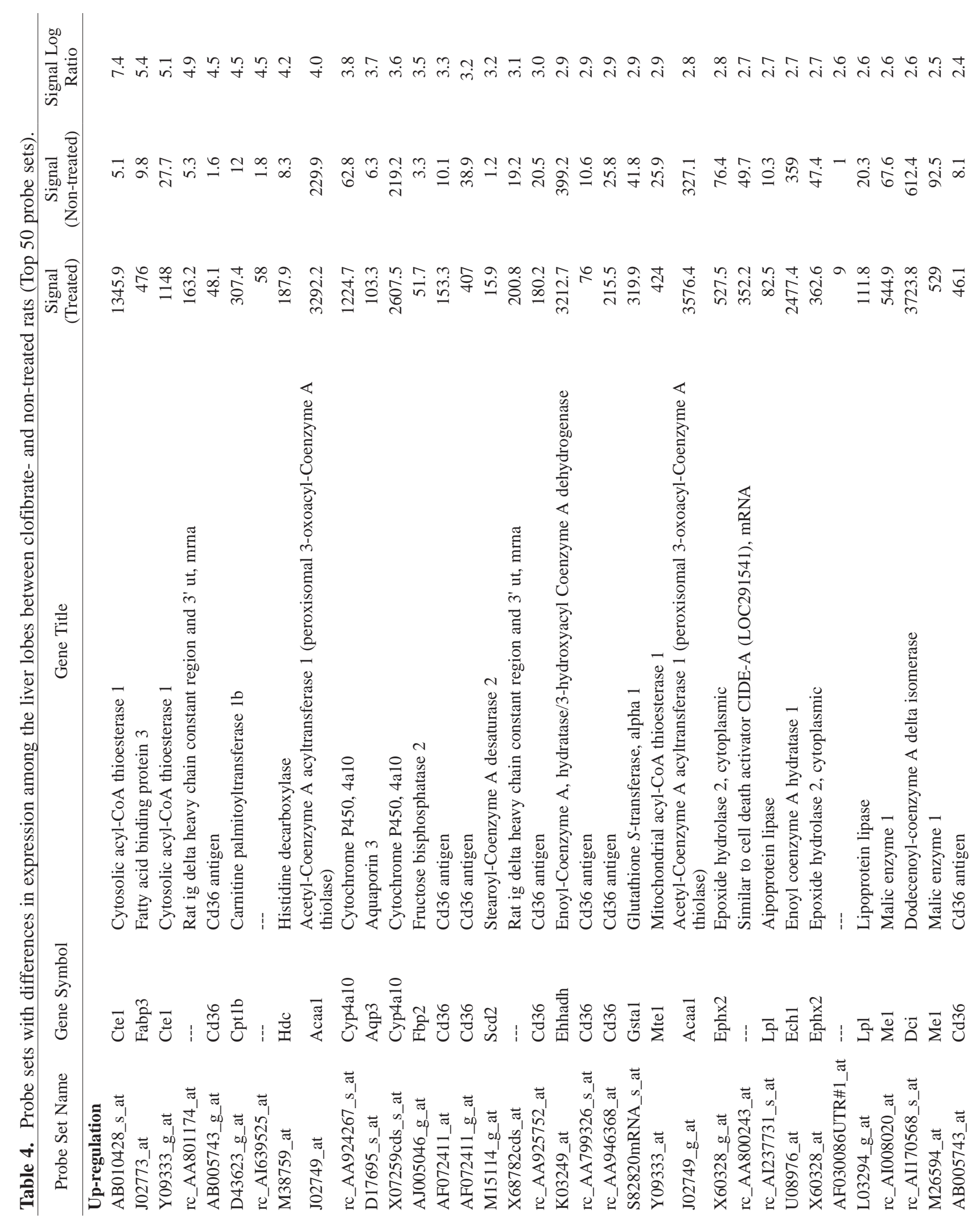


K. SUMIDA et al.

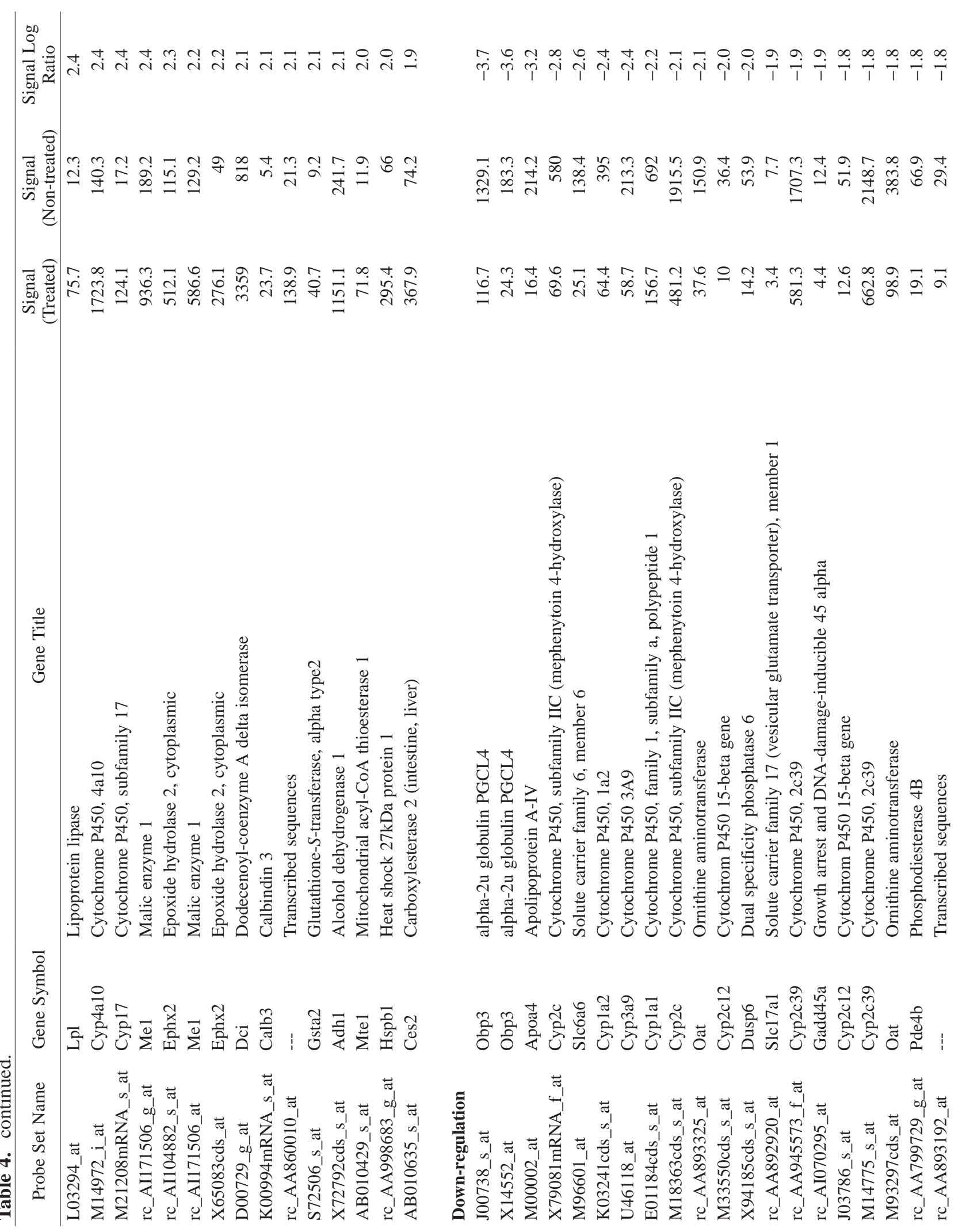


Optimization of an animal test protocol for toxicogenomics studies.

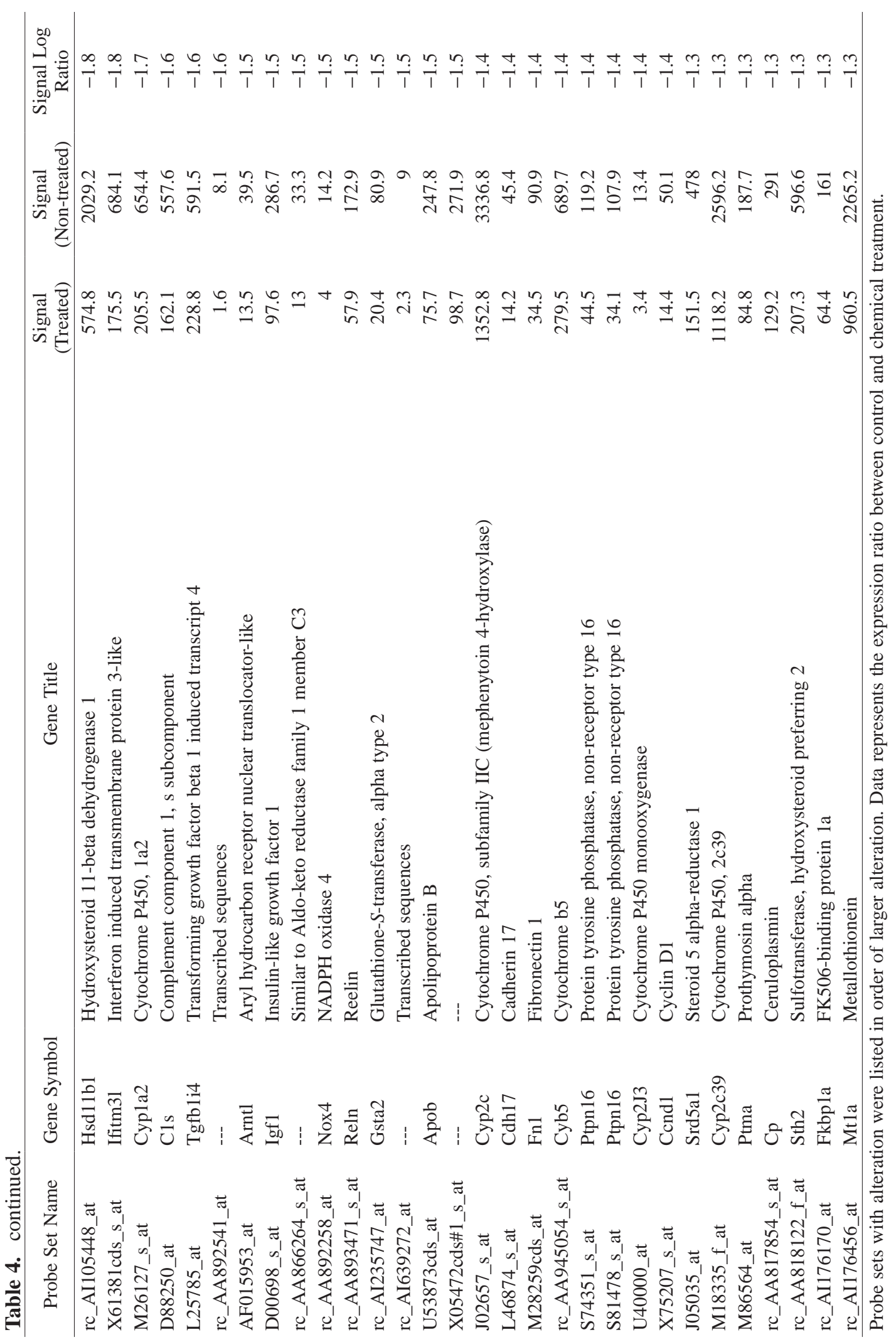


percentage of probe sets having discordant calls between two samples was less than $4.3 \%$ so that good concordance was obtained between freshly prepared RNA and stored or re-prepared RNA (tissue).

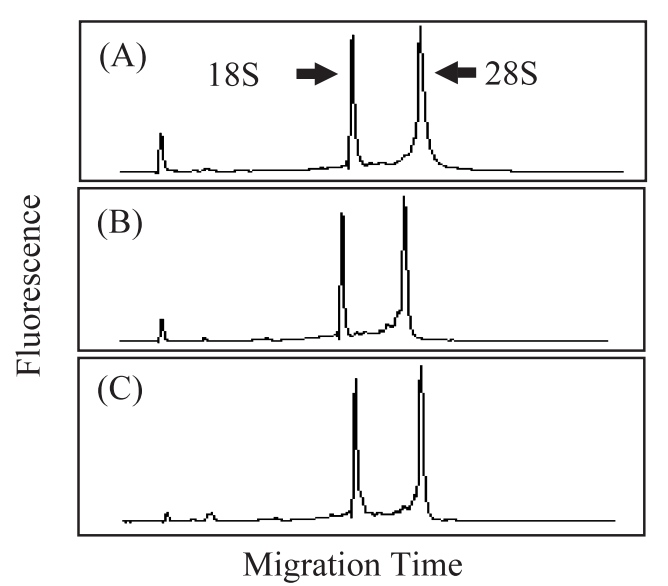

Fig. 2. Results of gel electrophoresis analysis of total RNA samples. The ribosomal ratio (28S to $18 \mathrm{~S}$ ) was measured using an Agilent 2100 Bioanalyzer for samples of total RNA from livers of male Fischer 344 rats given $50 \mathrm{mg} / \mathrm{kg} / \mathrm{day}$ carbon tetrachloride for 14 days. (A) Freshly prepared total RNA. (B) Total RNA kept at $-80^{\circ} \mathrm{C}$ for 2.5 years. (C) Re-prepared RNA from tissue kept at $-20^{\circ} \mathrm{C}$ in RNA for 2.5 years.
To further investigate the reproducibility among freshly prepared total RNAs, comparison and Signal Log Ratio concordance analyses were performed with samples kept at $-80^{\circ} \mathrm{C}$ for 2.5 years and re-prepared RNA from tissues kept at $-20^{\circ} \mathrm{C}$ in RNA later for 2.5 years (see Table 6). The percentage of probe sets demonstrating alteration in gene expression between paired samples was less than $1.6 \%$ and no significant differences in gene expression levels were observed. The results of the Signal Log Ratio concordance analysis are shown in Fig. 4. Samples were total RNA from livers of male Fischer 344 rats given $250 \mathrm{mg} / \mathrm{kg}$ /day clofibrate for 14 days. The altered probe sets, which were up- or down-regulated more than 2-fold on comparison between vehicle control and treatment groups, are plotted. The graphs show that the up-regulated probe sets demonstrated better correlation than their down-regulated counterparts. The obtained $\mathrm{R}^{2}$ values were 0.8767 and 0.8967 and the data thus comprehensively demonstrated good Signal Log Ratio concordance between samples.

Many probe sets were up- or down-regulated by clofibrate treatment, examples being listed in Table 7 . Included in the up-regulated category is acyl-CoA oxidase, the rate-limiting enzyme of the hepatic peroxisomal $\beta$-oxidation pathway (Baker et al., 2004). RGU34A includes two probe sets for acyl-CoA oxidase and both probe sets showed "I (increase)" with all
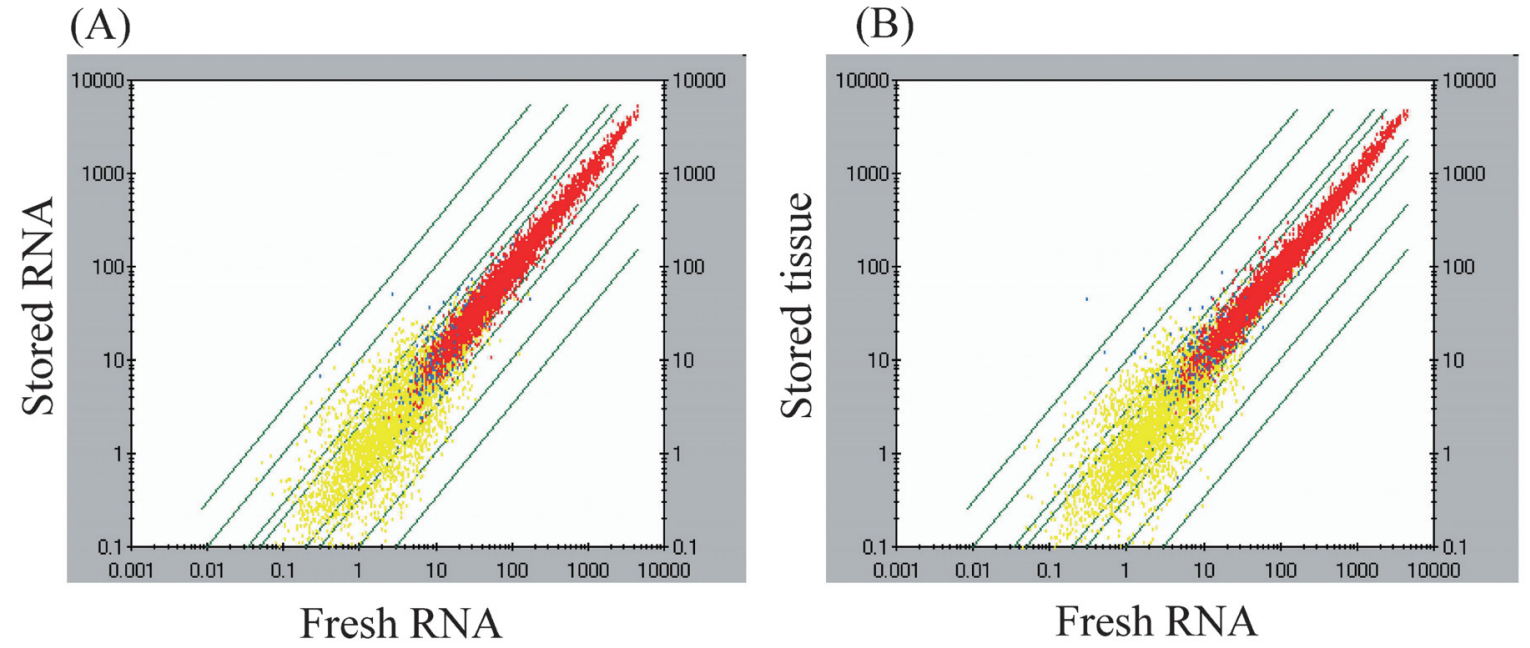

Fig. 3. Results of gene expression analysis of total RNA samples. Samples were total RNA from livers of male Fischer 344 rats which were given $50 \mathrm{mg} / \mathrm{kg} /$ day carbon tetrachloride for 14 days. (A) Scatter plot between freshly prepared total RNA and total RNA kept at $-80^{\circ} \mathrm{C}$ for 2.5 years. (B) Scatter plot between freshly prepared total RNA and re-prepared RNA from tissues kept at $-20^{\circ} \mathrm{C}$ in RNA later for 2.5 years. 
Optimization of an animal test protocol for toxicogenomics studies.

three samples. Malic enzyme, a lipogenic enzyme, and acyl-CoA thioesterase, which hydrolyzes acyl-CoAs to the corresponding free fatty acid plus coenzyme $\mathrm{A}$, are also up-regulated by clofibrate in rats (Karbowska et al., 1999; Hunt et al., 2000). There are four and two probe sets, respectively, for these enzymes on RGU34A and each showed a high Signal Log Ratio in all samples. Kramar et al. reported enhancement of aldehyde dehydrogenase activity in rat liver by clofibrate feeding (Kramar and Kremser, 1984) and its mRNA was observed to be increased by clofibrate treatment in our study. Stearoyl-CoA desaturase is a key enzyme in fatty acid biosynthesis whose gene expression is known to be modulated by clofibrate in mouse liver (Miller and Ntambi, 1996), while apolipoprotein-I and apolipoprotein-IV gene expression is decreased in rats treated with clofibrate (Staels et al., 1996). Probe sets for these apolipoproteins showed "D (decrease)" for all three samples. The data thus demonstrated good change call concordance between freshly prepared RNA and stored RNA or re-prepared RNA (tissue).

\section{Deterioration of RNA with freezing and thawing}

It is important to analyze the degree of RNA degradation by freezing and thawing repeatedly, since this

Table 5. Detection call concordance analysis.

\begin{tabular}{|c|c|c|c|c|c|c|c|}
\hline \multicolumn{4}{|c|}{$\bar{A}$} & \multicolumn{4}{|l|}{ B } \\
\hline & & \multicolumn{2}{|c|}{ Stored RNA } & & & \multicolumn{2}{|c|}{ Stored tissue } \\
\hline & & $\mathrm{P}$ & $\mathrm{A}$ & & & $\mathrm{P}$ & $\mathrm{A}$ \\
\hline \multirow{2}{*}{ Fresh RNA } & $\mathrm{P}$ & $42 \%$ & $0.9 \%$ & \multirow{2}{*}{ Fresh RNA } & $\mathrm{P}$ & $42 \%$ & $0.9 \%$ \\
\hline & A & $3.4 \%$ & $50 \%$ & & A & $2.3 \%$ & $51 \%$ \\
\hline
\end{tabular}

Samples were total RNAs from livers of male F344 rats, which were given $50 \mathrm{mg} / \mathrm{kg} /$ day carbon tetrachloride for 14 days. (A) Detection call concordance between freshly prepared total RNA and total RNA kept at $-80^{\circ} \mathrm{C}$ for 2.5 years. (B) Detection call concordance between freshly prepared total RNA and re-prepared RNA from tissues kept at $-20^{\circ} \mathrm{C}$ with RNAlater for 2.5 years.

(A)

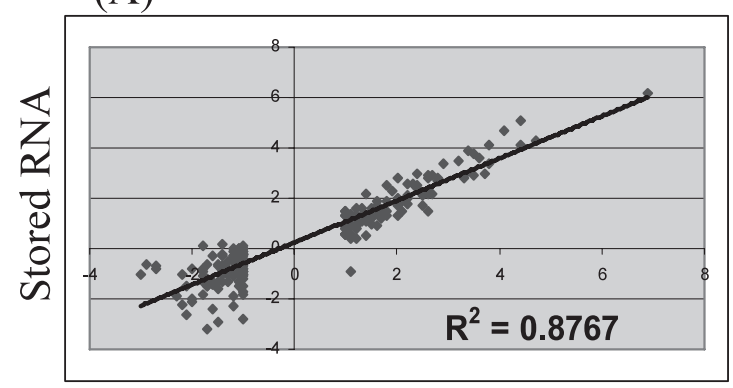

Fresh RNA
(B)

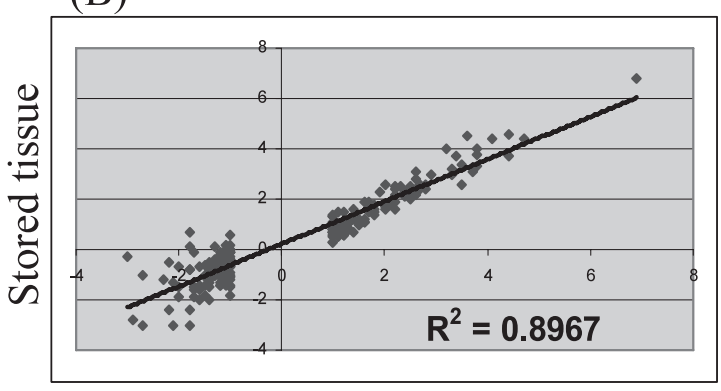

Fresh RNA

Fig. 4. Signal Log Ratio concordance analysis. Samples were total RNAs from livers of male Fischer 344 rats given $250 \mathrm{mg} / \mathrm{kg} /$ day clofibrate for 14 days or maintained as controls. Altered probe sets, which were up- or downregulated more than 2-fold on comparison between vehicle control and treatment groups, are plotted. (A) Freshly prepared total RNA versus total RNA kept at $-80^{\circ} \mathrm{C}$ for 2.5 years. (B) Freshly prepared total RNA versus re-prepared RNA from tissues kept at $-20^{\circ} \mathrm{C}$ in RNA later for 2.5 years.

Table 6. Comparison analysis between freshly prepared RNA and stored RNA or re-prepared RNA (tissue).

\begin{tabular}{cccccc}
\hline \multirow{2}{*}{ Chemicals } & \multirow{2}{*}{ Samples } & \multirow{2}{*}{ Storage } & $\begin{array}{c}\text { No Change } \\
(\%)\end{array}$ & $\begin{array}{c}\text { More than 2-fold } \\
(\%)\end{array}$ & $\begin{array}{c}\text { Less than } 1 / 2 \\
(\%)\end{array}$ \\
\hline \multirow{2}{*}{ Clofibrate } & & & 98.4 & 0.84 & 0.78 \\
& Stored RNA & & 98.8 & 1.01 & 0.15 \\
\multirow{2}{*}{ Carbon tetrachloride } & Re-prepared RNA (Stored tissue) & \multirow{2}{*}{2.5 years } & 99.8 & 0.13 & 0.11 \\
& Stored RNA & & 99.5 & 0.52 & 0.01 \\
\hline
\end{tabular}


K. SUMIDA et al.

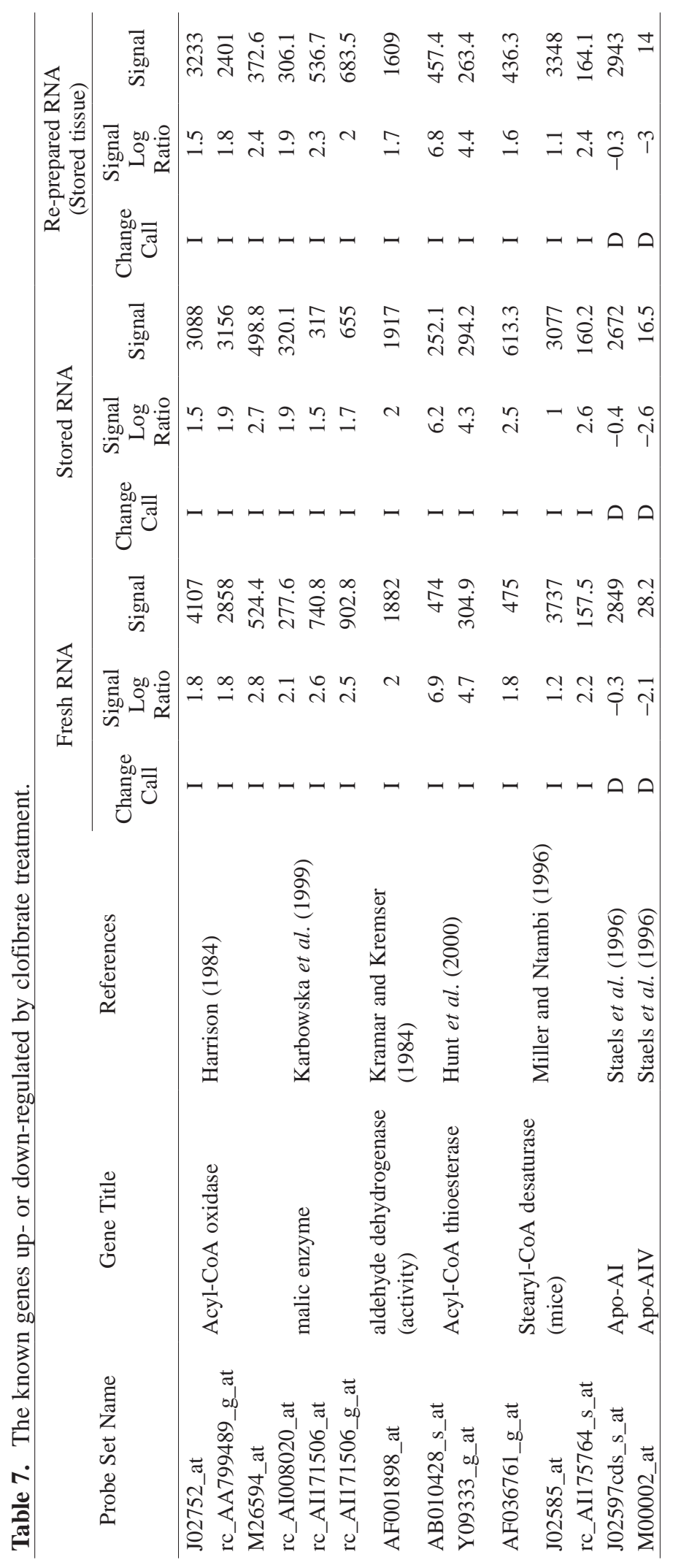


Optimization of an animal test protocol for toxicogenomics studies.
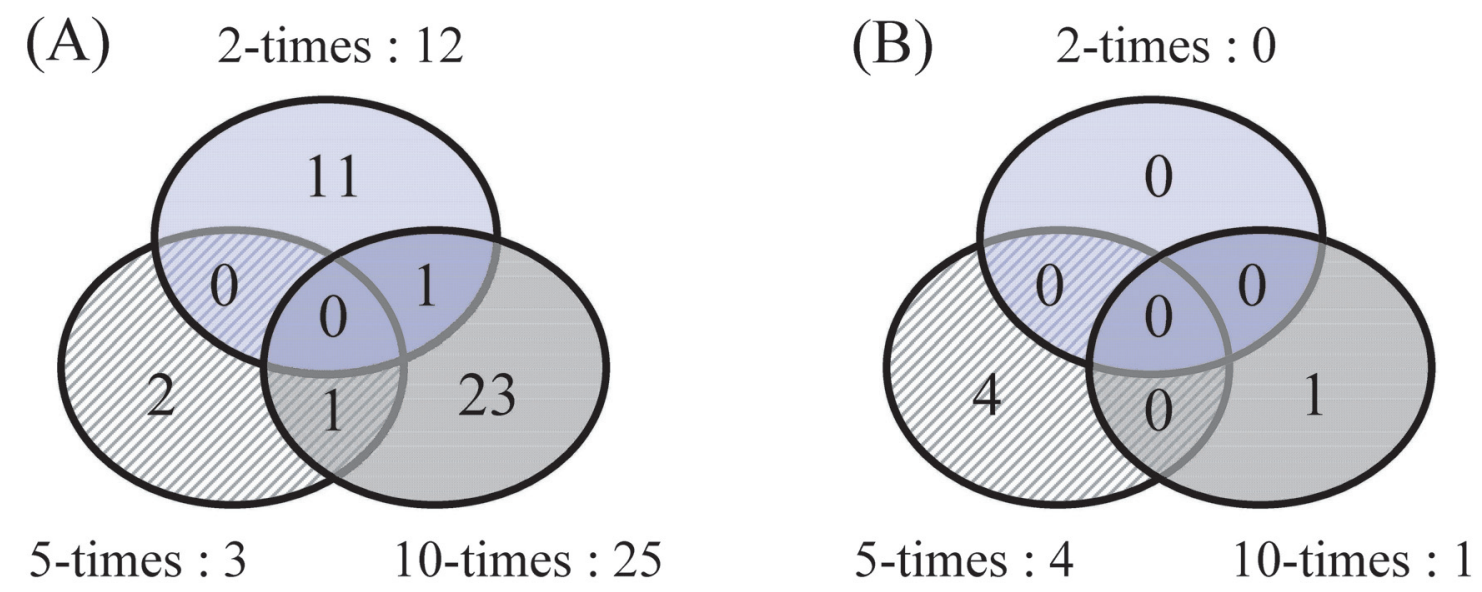

Fig. 5. Venn diagram of significant alteration in gene expression observed. Numbers represent probe sets with expression significantly altered. (A) Increased probe sets. (B) Decreased probe sets.

could greatly influence outcomes of gene expression analysis. To examine which probe sets were degraded by freezing and thawing, a rat was killed by decapitation and total RNA of liver was prepared with TRIzol reagent (Invitrogen). RNA samples, which were freeze-thawed 2, 5 or 10-times repeatedly, were taken for gene expression analysis and data were compared with findings for once freeze-thawed samples. There were 12 increased probe sets out of the total of 8799 in RGU34A in twice freeze-thawed samples, 3 increased and 4 decreased after 5 -times freeze-thawing, and 25 increased and 1 decreased after 10-times. Fig. 5 illustrates a Venn diagram of significant alterations in gene expression observed. There was no probe set that was overlapped in all times or in both 5- and 10-times so that it appeared that there was no specific probe set that was degraded by freezing and thawing. Since the Signal values of the listed probe sets were relatively low, the observed alteration in gene expression might be regarded as an experimental error.

To achieve success in our project, a reliable animal test protocol for toxicogenomics studies is very important. Regarding practical application, it is also essential that the quality of RNA and tissues stored in freezers be confirmed, with minimal deterioration of RNA by freezing and thawing. In the present study, we conducted a series of experiments to address these matters and here have proposed a reliable animal test protocol for toxicogenomics studies, which was improved by analyzing outcomes in our project. With regard to preparation of tissues and RNA, the results showed no RNA samples with degradation, even after a period of
2.5 years, and the quality of total RNA samples proved acceptable for DNA microarray analysis. It was also observed that there were no specific probe sets degraded by freezing and thawing and there were no significant differences in gene expression profiles when RNA samples were repeatedly freeze-thawed 10times.

\section{ACKNOWLEDGMENT}

The authors are grateful to Akiko Miyata, Masako Yoshikura, Yuki Tezuka, Emi Daira, Yukiko Miyama, Yukari Inoue and Kazuyo Tamaki of Environmental Health Science Laboratory, Sumitomo Chemical Co., Ltd. for their gene expression analysis in this work. The research was sponsored by the New Energy and Industrial Technology Development Organization (NEDO, Japan).

\section{REFERENCES}

Aviv, H. and Leder, P. (1972): Purification of biologically active globin messenger RNA by chromatography on oligothymidylic acid-cellulose. Proc. Natl. Acad. Sci. USA., 69, 1408-1412.

Baker, V.A., Harries, H.M., Waring, J.F., Duggan, C.M., Ni, H.A., Jolly, R.A., Yoon, L.W., De Souza, A.T., Schmid, J.E., Brown, R.H., Ulrich, R.G. and Rockett, J.C. (2004): Clofibrateinduced gene expression changes in rat liver: a cross-laboratory analysis using membrane cDNA arrays. Environ. Health Perspect., 112, 
428-438.

Hamadeh, H.K., Bushel, P.R., Jayadev, S., Martin, K., DiSorbo, O., Sieber, S., Bennett, L., Tennant, R., Stoll, R., Barrett, J.C., Blanchard, K., Paules, R.S. and Afshari, C.A. (2002): Gene expression analysis reveals chemical-specific profiles. Toxicol Sci., 67, 219-231.

Hunt, M.C., Lindquist, P.J., Nousiainen, S., Huttunen, M., Orii, K., Svensson, T.L., Aoyama, T., Hashimoto, T., Diczfalusy, U. and Alexson, S.E. (2000): Acyl-CoA thioesterases belong to a novel gene family of peroxisome proliferatorregulated enzymes involved in lipid metabolism. Cell Biochem. Biophys., 32, 317-324.

Jung, J.W., Park, J.S., Hwang, J.W., Kang, K.S., Lee, Y.S., Song, B.S., Lee, G.J., Yeo, C.D., Kang, J.S., Lee, W.S., Jeon, K.S., Um, C.H., Kim, Y.S., Oh, M.J., Youn, J.P., Li, P., Park, J.E. and Hwang, S.Y. (2004): Gene expression analysis of peroxisome proliferators- and phenytoininduced hepatotoxicity using cDNA microarrays. J. Vet. Med. Sci., 66, 1329-1333.

Kramer, J.A., Blomme, E.A., Bunch, R.T., Davila, J.C., Jackson, C.J., Jones, P.F., Kolaja, K.L. and Curtiss, S.W. (2003): Transcription profiling distinguishes dose-dependent effects in the livers of rats treated with clofibrate. Toxicol. Pathol., 31, 417-431.

Kramar, R. and Kremser, K. (1984): Enhancement of aldehyde dehydrogenase activity in rat liver by clofibrate feeding. Enzyme, 31, 17-20.

Karbowska, J., Kochan, Z., Zelewski, L. and
Swierczynski, J. (1999): Tissue-specific effect of clofibrate on rat lipogenic enzyme gene expression. Eur. J. Pharmacol., 370, 329-336.

Lockhart, D.J., Dong, H., Byrne, M.C., Follettie, M.T., Gallo, M.V., Chee, M.S., Mittmann, M., Wang, C., Kobayashi, M., Horton, H. and Brown, E.L. (1996): Expression monitoring by hybridization to high-sensity oligonucleotide arrays. Nature Biotechnol., 14, 1675-1680.

Miller., C.L., Diglisic, S., Leister, F., Webster, M. and Yolken, R.H. (2004): Evaluating RNA status for RT-PCR in extracts of postmortem human brain tissue. BioTechniques, 36, 628-633.

Miller, C.W. and Ntambi, J.M. (1996): Peroxisome proliferators induce mouse liver stearoyl-CoA desaturase 1 gene expression. Proc. Natl. Acad. Sci. USA, 93, 9443-9448.

Sambrook, J. and Russell, D.W. (2001): Molecular Cloning: A laboratory Manual, Vol. 1. CSH Laboratory Press, NY.

Schoor, O., Weinschenk, T., Hennenlotter, J., Corvin, S., Stenzl, A., Rammensee, H.G. and Stevanovic, S. (2003): Moderate degradation does not preclude microarray analysis of small amounts of RNA. BioTechniques, 35, 11921201.

Staels, B., Van Tol, A., Fruchart, J.C. and Auwerx, J. (1996): Effects of hypolipidemic drugs on the expression of genes involved in high density lipoprotein metabolism in the rat. Isr. J. Med. Sci., 32, 490-498. 